\title{
Maxillary sinus septa: A systematic review
}

\author{
Laura Maestre-Ferrín ${ }^{1}$, Sónnica Galán-Gil ${ }^{2}$, Minerva Rubio-Serrano ${ }^{2}$, María Peñarrocha-Diago ${ }^{3}$, David \\ Peñarrocha-Oltra ${ }^{1}$
}

\author{
${ }^{1}$ Student of Master of Oral Surgery and Implantology. Valencia University Medical and Dental School \\ ${ }^{2}$ Master of Oral Surgery and Implantology. Valencia University Medical and Dental School \\ ${ }^{3}$ Associate Professor of Oral Surgery. Master of Oral Surgery and Implantology. Valencia University Medical and Dental \\ School
}

Correspondence:

Clínicas odontológicas

Gascó Oliag 1

46021-Valencia (Spain)

Maria.Penarrocha@uv.es

\author{
Maestre-Ferrín L, Galán-Gil S, Rubio-Serrano M, Peñarrocha-Diago M, \\ Peñarrocha-Oltra D. Maxillary sinus septa: A systematic review. Med \\ Oral Patol Oral Cir Bucal. 2010 Mar 1;15 (2):e383-6. \\ http://www.medicinaoral.com/medoralfree01/v15i2/medoralv15i2p383.pdf

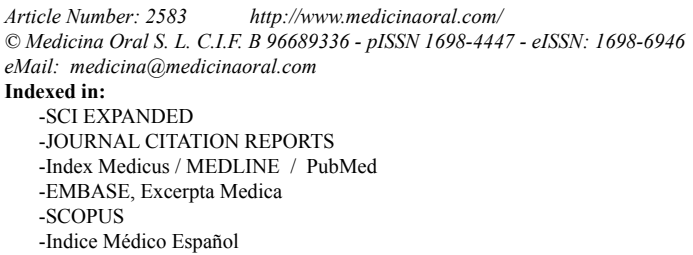

\begin{abstract}
This review analyzes articles published on the presence of septa in maxillary sinuses. An automated search was conducted on PubMed using different key words. This search resulted in 11 papers in which the presence of antral septa was assessed. These septa are barriers of cortical bone that arise from the floor or from the walls of the sinus and may even divide the sinus into two or more cavities. They may originate during maxillary development and tooth growth, in which case they are known as primary septa; or they may be acquired structures resulting from the pneumatization of maxillary sinus after tooth loss, in which case they are called secondary septa. Several methods have been used in their study, direct observation on dried skulls or during sinus lift procedures; and radiographic observation using panoramic radiographs or computed tomographs. Between 13 and $35.3 \%$ of maxillary sinuses have septa. They can be located in any region of the maxillary sinus and their size can vary between 2.5 and $12.7 \mathrm{~mm}$ in mean length. Some authors have reported a higher prevalence of septa in atrophic edentulous areas than in non-atrophic ones. If a sinus lift is conducted in the presence of maxillary sinus septa, it may be necessary to modify the design of the lateral window in order to avoid fracturing the septa.
\end{abstract}

Key words: Antral septa, maxillary sinus septa, membrane perforation.

\section{Introduction}

The presence of anatomic variations within the maxillary sinus, such as septa, have been reported to increase the risk of sinus membrane perforation during sinus elevation procedures (1-4).

Maxillary sinus septa were first described by Underwood in 1910 (5). They are walls of cortical bone within the maxillary sinus, their shape has been described as an inverted gothic arch arising from the inferior or late- ral walls of the sinus, and may even divide the sinus into two or more cavities.

Radiographic identification of these structures is important, since the design of the lateral window during sinus lift procedures is based on the presence and size of maxillary sinus septa (4).

The purpose of this review was to analyze articles published on the presence of septa in maxillary sinuses. 


\section{Search Strategy}

An automated search was conducted in PubMed using different key words: maxillary sinus septa, sinus lift, maxillary sinus anatomy, paranasal sinus septa. The last search was conducted on July, 21st of 2008.

Eleven papers published and indexed in MedlinePubMed, assessing presence of antral septa were found (2,3,5-13).

\section{Septa origin: Classification}

According to Underwood (5), the maxillary sinus floor is frequently divided into three basins: a small anterior one over the premolar region; a large median one descending between the roots of the first and second molars, and a small posterior one corresponding to the third molar region. These three sections of the floor of the sinus, which are often marked off by ridges, rising sometimes to distinct septa, correspond to three defined periods of tooth activity, separated by intervals of time: the anterior portion corresponds to the position of the eruption of the milk molars (between 8 months and 2 years); the middle portion corresponds to the eruption of the first and second permanent molars (from 5 to 12 years); and the posterior, corresponds to the eruption of the third molars (16 to 30 years) (5). The origin of these septa is wholly dental, and is due to the persistence of the intervening partitions when the rest of the bony floor sinks down between the dental roots during tooth eruption, leading to the location of septa between the roots of two adjacent teeth (5). Underwood (5) observed the existence of another type of septa, indicating that it must have a different origin as it seemed to be unrelated with teeth.

Krennmair et al. (8) classified septa into primary and secondary: primary septa corresponding to those first described by Underwood, arising from the development of the maxilla; and secondary septa arising from irregular pneumatization of the sinus floor following tooth loss.

Other authors (10-12), when observing maxillary sinus septa, classified them as primary septa if they were located superior to a maxillary tooth; and other septa, for septa located superior to an edentulous ridge, as they could be either primary or secondary septa, or a combination of both types.

\section{Septa study methodology}

Observation methods used by the different authors are shown in (Table 1). Underwood (5) was the first to study maxillary sinus septa; he examined 45 dried skulls cut at the level of the maxillary sinus. Ulm et al. (3) conducted an observational study on the septa of 41 edentulous maxillae during sinus lift procedures. Lugmayr et al. (6) studied the presence and morphology of maxillary sinus septa by observing the CTs of 100 adult patients. Krennmair et al. (7) assessed the prevalence of septa in 265 maxillary sinuses; 65 were observed during sinus lifting, using the same method as Ulm et al. (3); and 200 sinuses were examined radiologically by CT. In 1999, the same group of authors (8) carried out another study of 194 posterior maxillary regions, which were divided into 4 groups: group 1, clinically observed during sinus lift maneuvers and with panoramic radiographs; group 2, skulls for anatomic study; group 3, atrophic ridges studied with TC; group 4, CT of dentate maxillary ridges. Kasabah et al. (9) conducted a radiologic study of septa comparing panoramic radiograph with CT. In the same year, Velásquez-Plata et al. (10) utilized SIM/ Plant software to analyze CT images of 312 sinuses; the presence of septa was determined using axial planes of section and the panoramic reconstructions were used to assess the height of the septa. Axial plane images were utilized to locate the segment to be measured in the lateral, middle, and medial aspects of the septa; septa measuring more than $2.5 \mathrm{~mm}$ in height at 1 of 3 positions measured were included in the analysis. Kim et al. (11) studied the reformatted computed tomograms from 200 sinuses, which were analyzed using an automated image analysis system; following the same procedure as Velásquez-Plata et al. (10). González-Santana et al. (12) assessed the prevalence of septa in panoramic radiographs and CTs of 30 patients. Shibli et al. (13) reported the prevalence of maxillary sinus septa in totally edentulous patients, with 1024 panoramic radiographs observed by three examiners.

Krennmair et al. (8) compared the number of septa localized in panoramic radiographs with the real number of septa detected during the surgery; panoramic radiographs lead to a false diagnosis in $21.3 \%$ of the cases. Kasabah et al. (9) and González-Santana et al. (12) compared septa diagnosed on panoramic radiographs with septa diagnosed by CTs; they found a false diagnosis with panoramic radiographs in $44.1 \%$ and $11.8 \%$ of the cases, respectively (Table 1). These results demonstrated the low reliability of panoramic radiographs in the detection of maxillary sinus septa.

\section{Prevalence}

The prevalence of septa can be calculated based on either the number of sinuses which have septa or on the number of patients who have septa.

In studies based on the number of sinuses, the prevalence varies between 13 and $35.3 \%(3,6-12)$. In studies based on the number of patients, it varies between 21.6 and $66.7 \%(5,10-13)$ (Table 2).

\section{Location}

Underwood (5) noted that the location of the septa inside the sinus is repeated in different individuals due to their development at three different moments of tooth erruption. He described three areas for septa location: anterior, between the roots of second premolar and first molar; middle, between the roots of first and second 
Table 1. Methods for the study of maxillary sinus septa (OPT: panoramic radiograph).

\begin{tabular}{|l|c|c|c|c|c|}
\hline \multicolumn{1}{|c|}{ Author } & Year & OPT & CT & In situ & $\begin{array}{c}\text { OPT mistakes } \\
\text { (\%) }\end{array}$ \\
\hline Underwood (5) & 1910 & No & No & Yes & - \\
\hline Betts and Miloro (2) & 1994 & No & No & Yes & - \\
\hline Ulm et al. (3) & 1995 & No & No & Yes & - \\
\hline Lugmayr et al. (6) & 1996 & No & Yes & No & - \\
\hline Krennmair et al. (7) & 1997 & No & Yes & Yes & - \\
\hline Krennmair et al. (8) & 1999 & Yes & Yes & Yes & $21.3 \%$ \\
\hline Kasabah et al. (9) & 2002 & Yes & Yes & No & $44.1 \%$ \\
\hline $\begin{array}{l}\text { Velásquez-Plata et al. } \\
(10)\end{array}$ & 2002 & No & Yes & No & - \\
\hline Kim et al. (11) & 2006 & No & Yes & No & - \\
\hline $\begin{array}{l}\text { González-Santana et al. } \\
(12)\end{array}$ & 2007 & Yes & Yes & No & $11.8 \%$ \\
\hline Shibli et al. (13) & 2007 & Yes & No & No & - \\
\hline
\end{tabular}

Table 2. Summary of septa prevalence and location. (Preval: \% Pt: prevalence based on the number of patients; Preval: \% sinus: prevalence based on the number of sinuses).

\begin{tabular}{|c|c|c|c|c|c|c|c|}
\hline Author & Year & $\begin{array}{l}N^{o} \text { pa- } \\
\text { tients }\end{array}$ & $\begin{array}{c}\mathrm{N}^{\mathrm{o}} \\
\text { septa }\end{array}$ & $\begin{array}{l}\text { Preval. \% } \\
\text { Pt. }\end{array}$ & $\begin{array}{l}\text { Preval. } \\
\text { \% sinus }\end{array}$ & $\begin{array}{l}\text { Most com- } \\
\text { mon region }\end{array}$ & Patient edentulism \\
\hline Underwood (5) & 1910 & 45 & 30 & 66.7 & $33.3 \%$ & Posterior & - \\
\hline Betts and Miloro (2) & 1994 & - & 20 & - & - & - & - \\
\hline Ulm et al. (3) & 1995 & 41 & 13 & - & 31.7 & Anterior & Total \\
\hline Lugmayr et al. (6) & 1996 & 100 & 26 & - & 13 & - & - \\
\hline Krennmair et al. (7) & 1997 & 165 & 50 & - & 18.8 & - & $\begin{array}{c}\text { Partial, total and } \\
\text { dentate }\end{array}$ \\
\hline Krennmair et al. (8) & 1999 & 97 & 51 & - & 26.3 & Anterior & Partial and total \\
\hline Kasabah et al. (9) & 2002 & 34 & 26 & - & 35.3 & - & - \\
\hline $\begin{array}{l}\text { Velásquez-Plata et } \\
\text { al. (10) }\end{array}$ & 2002 & 156 & 75 & 32,7 & 24 & Middle & Partial and total \\
\hline Kim et al. (11) & 2006 & 100 & 59 & 38 & 26.5 & Middle & Partial and total \\
\hline $\begin{array}{l}\text { González-Santana et } \\
\text { al. (12) }\end{array}$ & 2007 & 30 & 17 & 36.7 & 25 & Middle & Partial and total \\
\hline Shibli et al. (13) & 2007 & 1024 & 307 & 21.58 & - & - & Total \\
\hline
\end{tabular}

permanent molars; and posterior, distal aspect of third molar roots.

Krennmair et al. (8) divided the maxillary sinus floor into three other regions: anterior, corresponds to the premolar area; middle, superior to the first molar; and posterior, in the area of the second molar.

The sinus division made by Velásquez-Plata et al. (10) was: anterior region, between the mesial aspect and distal aspect of the second premolar root; middle, between distal aspects of second premolar and second molar; and posterior, distal aspect of the root of the second molar.
The same division was used by Kim et al. (11).

González-Santana et al. (12) divided the sinus into three parts by drawing two straight lines perpendicular to the floor of the sinus, and at the same distance from the anterior and posterior walls of the sinus, thus they obtained three regions: anterior, middle and posterior.

For Underwood (5), the most common location for septa, was the posterior region; for Ulm et al. (3) and Krennmair et al. $(7,8)$, the anterior one; and for VelásquezPlata et al. (10), Kim et al. (11) and González-Santana et al. (12), the middle region. 


\section{Height}

Ulm et al. (3) considered the existence of septa if they measured more than $2.5 \mathrm{~mm}$; this criterion has been followed by several groups of authors (9-12).

Underwood (5) reported a mean height of septa between 6.4 and $12.7 \mathrm{~mm}$. Velásquez-Plata et al. (10) assessed each septa at three points: the mean height for the lateral aspect was $3.5 \mathrm{~mm} ; 5.9 \mathrm{~mm}$ for the central aspect; and $7.6 \mathrm{~mm}$ for the medial one. Kim et al. (11) used the same method as Velásquez-Plata et al., they reported mean heights of $1.6 \mathrm{~mm}$ in the lateral aspect, of $3.5 \mathrm{~mm}$ in the middle aspect and 5.5 in the medial one. GonzálezSantana et al. (12) registered heights between 2.5 and $6 \mathrm{~mm}$.

Some groups of authors $(7,8,10,11)$ agree when comparing septa from totally edentulous areas with septa from partially edentulous ones, they found higher septa in partially edentulous areas, with statistically significant differences. Velásquez-Plata et al. (10) and Kim et al. (11) compared primary septa and other septa of partially edentulous patients: Kim et al. (11) found significantly greater heights in primary septa, whereas VelásquezPlata et al. found that primary septa were significantly shorter (10).

Is there any relation between the presence of septa and age, sex or type of edentulism?.

The prevalence of septa has no relation with patients sex or age (13), but there are differences based on the type of edentulism; some studies reported a higher prevalence of septa in totally edentulous/atrophic areas than in partially edentulous/non-atrophic ones, with statistically significant differences $(8,11)$. According to Kim et al. (11) this is because atrophic/edentulous maxillary segments generally contain secondary septa.

\section{Handling of septa in maxillary sinus lift}

The sinus lift operation consists of the preparation of a top hinge window in the lateral maxillary sinus wall, this window is luxated inward and upward together with the Schneiderian membrane to a horizontal position forming the new sinus floor; the space between the old and the new floor is filled with graft material (14-16). The presence of maxillary sinus septa can complicate both the luxation of the window into the sinus and the lifting of the membrane (1). Boyne et al. (17) advises cutting the septa with a chisel and remove them with hemostatic forceps, so that the graft can be placed without interruption. Sometimes, it is necessary to modify the lateral window design to avoid fracturing the septa: if the septa is high it is advised to make two windows, one on each side $(2,4)$; or make one w-shaped window if the septa is lower (4).

\section{Conclusions}

Between 13 and $35.3 \%$ of maxillary sinuses have septa; to avoid complications during sinus lifting a meticulous study of the sinus is necessary, preferably by computed tomography, as panoramic radiography has been to shown to have a low sensibility and specificity in the identification of these structures.

\section{References}

1. Chanavaz M. Maxillary sinus: anatomy, physiology, surgery, and bone grafting related to implantology--eleven years of surgical experience (1979-1990). J Oral Implantol. 1990;16:199-209.

2. Betts NJ, Miloro M. Modification of the sinus lift procedure for septa in the maxillary antrum. J Oral Maxillofac Surg. 1994;52:332-3.

3. Ulm CW, Solar P, Krennmair G, Matejka M, Watzek G. Incidence and suggested surgical management of septa in sinus-lift procedures. Int J Oral Maxillofac Implants. 1995;10:462-5.

4. Van den Bergh JP, Ten Bruggenkate CM, Disch FJ, Tuinzing DB. Anatomical aspects of sinus floor elevations. Clin Oral Implants Res. 2000;11:256-65.

5. Underwood AS. An Inquiry into the Anatomy and Pathology of the Maxillary Sinus. J Anat Physiol. 1910;44:354-69.

6. Lugmayr H, Krennmair G, Holzer H. The morphology and incidence of maxillary sinus septa. Rofo. 1996;165:452-4.

7. Krennmair G, Ulm C, Lugmayr H. Maxillary sinus septa: incidence, morphology and clinical implications. J Craniomaxillofac Surg. 1997;25:261-5.

8. Krennmair G, Ulm CW, Lugmayr H, Solar P. The incidence, location, and height of maxillary sinus septa in the edentulous and dentate maxilla. J Oral Maxillofac Surg. 1999;57:667-71.

9. Kasabah S, Slezák R, Simůnek A, Krug J, Lecaro MC. Evaluation of the accuracy of panoramic radiograph in the definition of maxillary sinus septa. Acta Medica (Hradec Kralove). 2002;45:173-5.

10. Velásquez-Plata D, Hovey LR, Peach CC, Alder ME. Maxillary sinus septa: a 3-dimensional computerized tomographic scan analysis. Int J Oral Maxillofac Implants. 2002;17:854-60.

11. Kim MJ, Jung UW, Kim CS, Kim KD, Choi SH, Kim CK, et al. Maxillary sinus septa: prevalence, height, location, and morphology. A reformatted computed tomography scan analysis. J Periodontol. 2006;77:903-8.

12. González-Santana H, Peñarrocha-Diago M, Guarinos-Carbó J, Sorní-Bröker M. A study of the septa in the maxillary sinuses and the subantral alveolar processes in 30 patients. J Oral Implantol. 2007;33:340-3.

13. Shibli JA, Faveri M, Ferrari DS, Melo L, Garcia RV, D’Avila $\mathrm{S}$, et al. Prevalence of maxillary sinus septa in 1024 subjects with edentulous upper jaws: a retrospective study. J Oral Implantol. 2007;33:293-6.

14. Martos Díaz P, Naval Gías L, Sastre Pérez J, González García R, Bances del Castillo F, Mancha de la Plata M, et al. Sinus elevation by in situ utilization of bone scrapers: technique and results. Med Oral Patol Oral Cir Bucal. 2007;12:E537-41.

15. Aguirre Zorzano LA, Rodríguez Tojo MJ, Aguirre Urizar JM. Maxillary sinus lift with intraoral autologous bone and B--tricalcium phosphate: histological and histomorphometric clinical study. Med Oral Patol Oral Cir Bucal. 2007;12:E532-6.

16. González-García R, Naval-Gías L, Muñoz-Guerra MF, SastrePérez J, Rodríguez-Campo FJ, Gil-Díez-Usandizaga JL. Preprosthetic and implantological surgery in patients with severe maxillary atrophy. Med Oral Patol Oral Cir Bucal. 2005;10:343-54.

17. Boyne PJ, James RA. Grafting of the maxillary sinus floor with autogenous marrow and bone. J Oral Surg. 1980;38:613-6. 